\title{
Research on Innovation Ability Construction of Manufacturing Industry
}

\author{
Fei PENG ${ }^{a}{ }^{\star}$ and Bang-Cheng SUN
}

\author{
CRRC Industrial Institute Corporation Limited, Beijing, 100070 \\ apengfei@crrcgc.cc \\ ${ }^{*}$ Corresponding author
}

Keywords: Manufacturing industry, Innovation ability, Situation analysis, Construction strategy.

\begin{abstract}
This paper summarizes the situation of the technological innovation in China's manufacturing industry, analyzes the reasons of the problems from the perspectives of total factor productivity, financial level and technological innovation reserves. Based on the background of the construction of the innovative country, this paper puts forth some suggestions for the construction of innovative cluster in the manufacturing industry.
\end{abstract}

\section{Introduction}

Manufacturing industry is the main foundation industry of our country's economic development, and it is also the growth point of "economic new normal" of our country while adopting the innovation development strategy. Increasing the innovation ability can help to improve the global competitiveness of China's manufacturing industry, enhance the added value and overall production efficiency of the manufacturing products.

It was made clear in the nineteen major reports by president $\mathrm{Xi}$ in October 2017 that, China should accelerate the construction of the innovative country, strengthen basic research, realize the breakthrough achievements in the fields of forward-looking research and fundamental research. At present, although China's $R \& D$ investment is growing rapidly, there is still a big gap in $R \& D$ efficiency comparing with the power countries, especially in the manufacturing industry. It is urgent to enhance the overall innovation capability.

\section{Research Background}

Joseph Alois Schumpeter put forward the "innovation theory" in 1912, emphasizing innovation as creating a new production function, introducing the new combination of production conditions and elements into the existing production system. Innovation includes, but not limited to, new products, new technologies, new markets, new sources and new organizations. Furthermore, we focus innovation on technological progress process. Robert Solow and Paul Romer put forward the new classical economic growth model and endogenous economic growth theory in 1956 and 1986 respectively, and elaborated the two steps theory of technological innovation in detail. With the continuous development of social form, Asheim $\mathrm{T}$ put forward the network paradigm of technological innovation in 1998. It incorporated the external environment of innovation, information exchange and resource coordination into the category of technological innovation, and formed the concept of "regional innovation". Regional innovation consists of three parts: main elements, functional elements and environmental factors. The main elements include government, enterprises, research institutions, universities, etc. The functional elements include system innovation, management innovation and service innovation. Environmental factors include infrastructure, hardware environment, policies and regulations. With the further development of regional innovation, the concept of cluster innovation is formed by linking innovation with industrial clusters. The innovation network is not only the integration of industrial chain, enterprise chain and technology chain, but also the integration of value chain and data chain, forming a technology - economic network.

In terms of innovation capacity construction, Christensen puts forward that technological 
innovation capability can form scientific research assets, technological innovation assets, product innovation assets and aesthetic design assets from the perspective of upstream and downstream chain of innovation activities. Lawless and Fisher pointed out that the innovation involves learning, $\mathrm{R} \& \mathrm{D}$, manufacturing and marketing activities, and innovation ability should include learning ability, research ability, resource allocation ability, market ability, organizational ability and strategic planning ability.

After studying how the R\&D investment influence the production efficiency, Griliches put forward the knowledge production function model. The input variables including research funding, human resource, labor skill level and education level. Aghion and Howitt focused on the innovative investment factors influence towards the innovation performance, and found that the talent, technology, capital and information are essential elements of innovation, any individual investment increase will enhance innovation output respectively.

\section{The Situation China Innovation Ability}

Since the reform and opening-up, China's economic aggregate, especially the output value of the manufacturing industry, has been steadily increasing. During the "12th Five-Year" period, China's total industrial added value has increased by an average annual growth rate of $6.7 \%$. In 2016 , China's total industry increased by 24 trillion and 800 billion yuan, ranking the highest in the world. At the same time, the investment of R\&D and R\&D personnel in China has also maintained rapid growth. In 2016, the total investment in R\&D exceeded 1 trillion and 560 billion yuan, up $10.6 \%$ from the 2015, and the growth rate is 1.7 percentage points over the previous year. In terms of $R \& D$ personnel, in 2016, the total number of scientific and technological human resources in China exceeded 80 million people, and the number of scientific and technological personnel in every 10000 people exceeded 600. On the patent side, in 2016, China's Intellectual Property Office accepted 1 million 339 thousand invention patent applications (404 thousand authorized), an increase of $21.5 \%$ over the past year, ranking the top in the world in 6 consecutive years, of which the enterprises accounted for more than $60 \%$.

However, China is still not a manufacturing power country. The manufacturing industry mostly focuses on the bottom of the industrial value chain with a low added value. The technological innovation ability is weak, and the industrial innovation system is imperfection. According to the world bank's assessment of 81 indicators of 7 categories of 127 economies in the world, China's innovation index ranks 22, and the contribution rate of scientific and technological progress is only $56.2 \%$. According to the total factor productivity, China's economic growth mainly comes from capital and human input growth, as well as the development of scale economy and the improvement of resource allocation. Technological progress contributes less to economic growth and has a gradual downward trend in recent years. Compared with the developed countries, China's total factor productivity has larger fluctuation, as shown in Figure 1. As shown in Figure 2, in 2016, China's R\&D investment accounted for $2.1 \%$ of the total GDP, which has been increasing rapidly for 9 years, but over the same period, Israel and Korea exceed 4\%, Japan inputs more than 3\%, and US invests nearly $3 \%$. There is still a gap between China and the advanced countries. In terms of patent use, although the amount of invention patents has exceeded 1 million pieces in China, ranking third in the world, but the proportion of effective invention patents over 10 years is still low, and the rate of patent conversion is not high. In view of the more authoritative three-party patent number, according to the statistics of OECD, China accounted for only $3.3 \%$ of the world's total, far behind $29.7 \%$ of Japan and $27 \%$ of the US, as shown in Figure 3. 


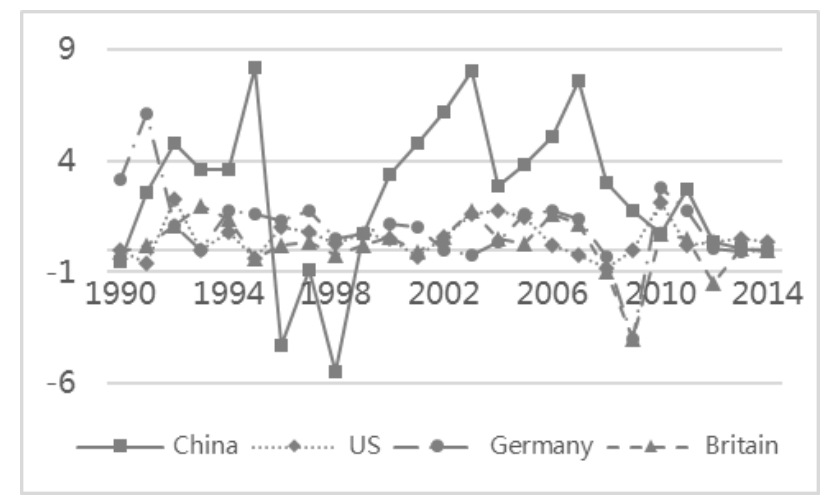

Fig.1 The change of TFP growth rate

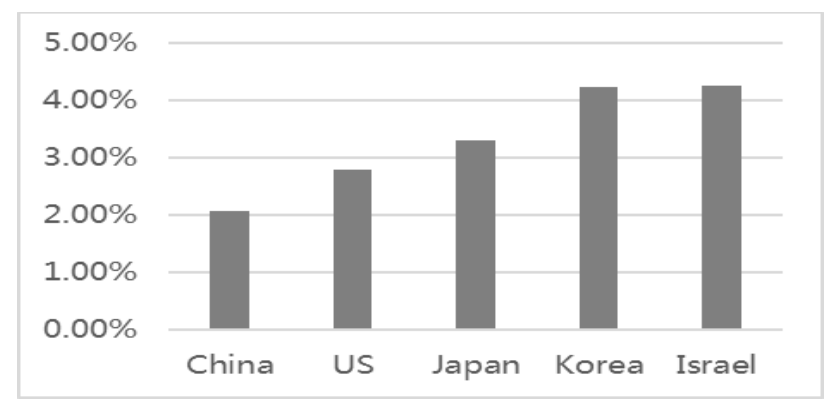

Fig.2 The GDP ratio of R\&D input of 2016

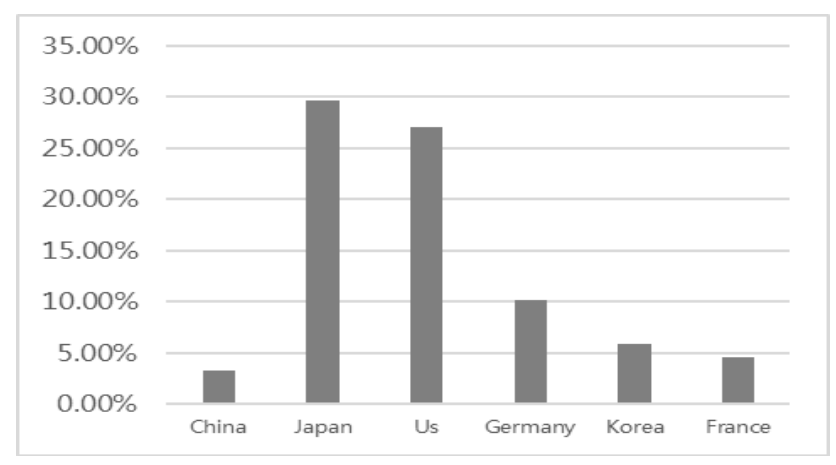

Fig.3 The proportion of three party patent in 2016

Taking the patent level and the total factor productivity as the reference index, this paper the analyze the problem during the innovation ability construction.

\section{Problem Analysis}

In this paper, we take the United States, Japan, Israel and other countries with strong technological innovation capabilities as reference, analyze the shortcomings of innovation capacity construction of Chinese manufacturing industry.

\section{R\&D Expenditure Structure}

Over the past 15 years, the expenditure of scientific research in China has increased rapidly at an annual average rate of $19.8 \%$. However, due to the small base, the R\&D investment proportion of GDP is still quite different from that of the world's recognized innovation countries. In the aspect of scientific research funding per personnel, due to a large research personnel, although China's R\&D funds in 2016 accounted for about $20 \%$ of the world, but the R\&D expenditure per personnel is 404 thousand yuan, only $62 \%$ of the United States, is also far behind Japan, Germany, South Korea, Israel and other countries. 
China is also faced with structural imbalance in the scientific research expenditure of different fields. As shown in Figure 4, according to the analysis report of PWC, the R\&D investment of manufacturing enterprises in China is nearly $40 \%$ in 2016, but the investment proportion of global innovation 1000 is only about $10 \%$, and the investment proportion of Asia is only $19 \%$. In the field of medicine and health, the proportion of global innovation 1000 is more than $20 \%$, Asia is $8 \%$, and China is only $1 \%$.

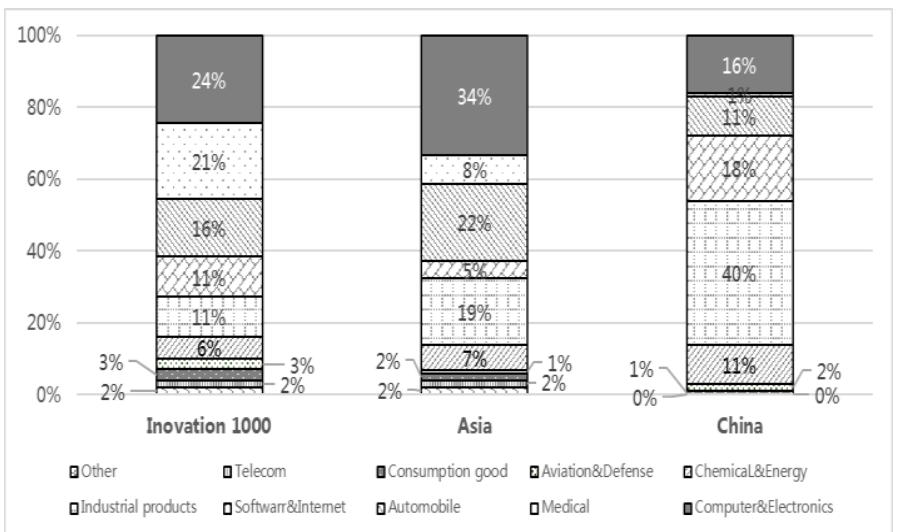

Fig.4 Comparison of the industry R\&D expenditure structure

In addition, the $\mathrm{R} \& \mathrm{D}$ expenditure structure in the enterprise is also imbalance. Take a high-end manufacturing enterprise as an example, as shown in Figure 5, the equipment cost is more than a half, and the proportion of equipment cost, material fee and testing cost is more than $88 \%$, which is significantly different from those of SIEMENS (Figure 5), which is recognized as an innovation enterprise. This indicates that the technological innovation of domestic enterprises is mainly based on experimental verification, resulting in a lot of experimental environment construction contents, such as equipment purchase and so on, while the proportion of funds actually used in innovation research is low.

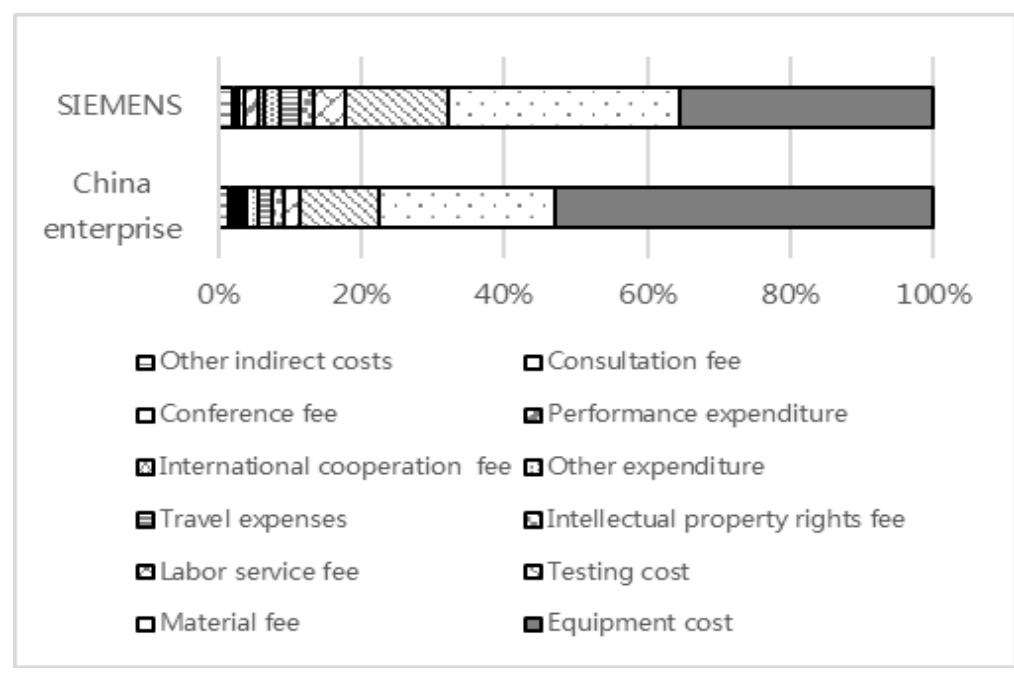

Fig.5 Comparison of enterprise R\&D expenditure structure

\section{Financial Support}

The innovation of technology cannot be separated from the capital investment. In addition to the endogenous funds of institutions and enterprises, external funds, especially the market oriented financing systems and mechanisms are more important. The participation of the market funds, not only benefit to connection of the early $R \& D$ process with the later market operation, but also improve the advance mining and utilization of the technological innovation, reduce the lack of enthusiasm caused by the mismatch between the innovation contribution and earnings.

The index of financial aggregation level includes four systems, including financial background, 
financial scale, financial density and financial depth, and ten indicators such as total economic activity and GDP per capita. This paper uses the level of financial aggregation as an evaluation index for the degree of regional financial market activity, and holds that the more active the financial market is, the more funds will be invested in technological innovation through financial channels.

This paper compares the relationship between financial aggregation level, total factor productivity and cumulative number of patents in different provinces of China. We find that the level of financial aggregation is positively related to cumulative number of patents and TFP, as shown in figures 6 and 7. The correlation coefficient between the 2016 patent ownership and the 2005-2010 average financial aggregation level is 0.724 , the correlation coefficient between the TFP of 1997-2007 and the 2005-2010 average financial aggregation level is 0.619.

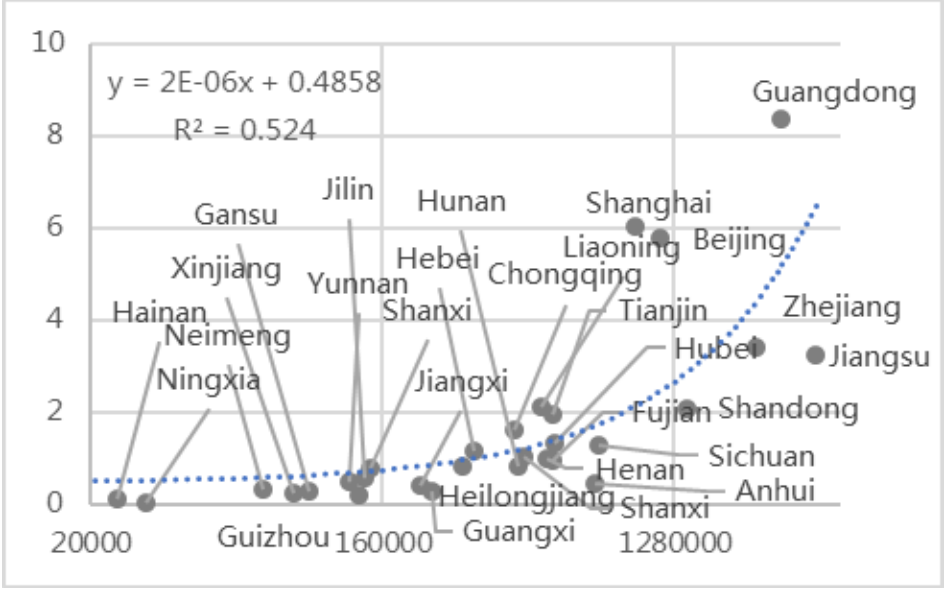

Fig.6 Relationship between Cumulative patent and financial aggregation level of 2016

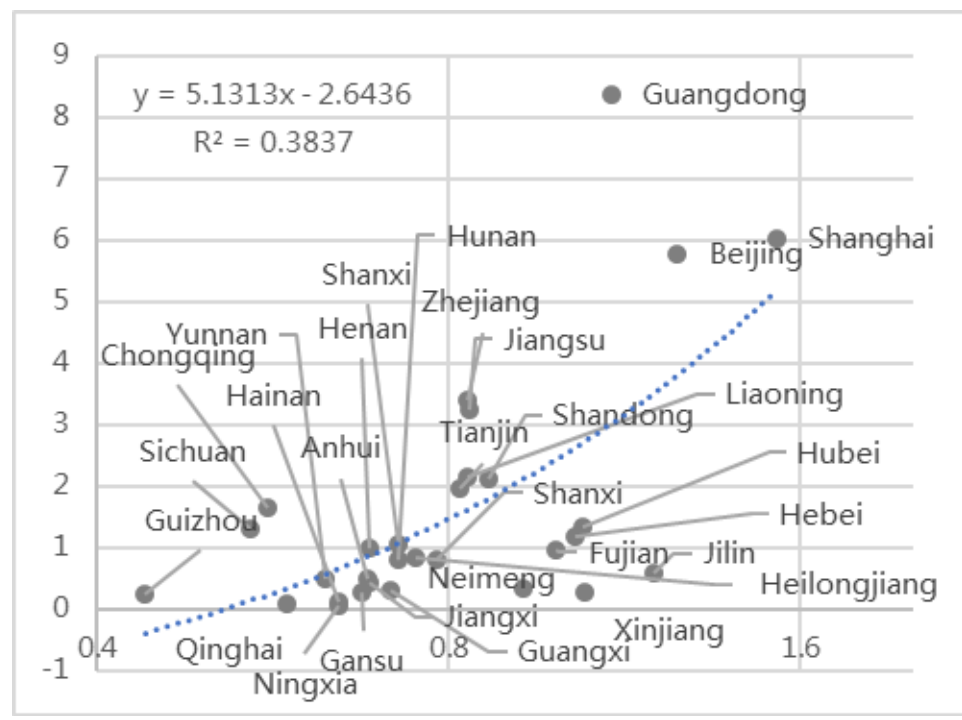

Fig.7 Relationship between TFP and financial aggregation level of 1997-2007

\section{Technological Innovation Reserves}

Technological innovation reserves are derived from the foundation research results, FDI and technology introduction.

The proportion of foundation research expenditure in China is relatively low. In 2016, the expenditure on foundation research in China was 82 billion 290 million yuan, up $14.9 \%$ from the previous year, accounting for $5.2 \%$ of the total $\mathrm{R} \& \mathrm{D}$ expenditure, which is the highest level in nearly ten years, shown in Figure 8. However, it is still lower than the developed countries which the proportion of foundation research expenditure level is 10\%-20\%, as shown in Figure 9. 


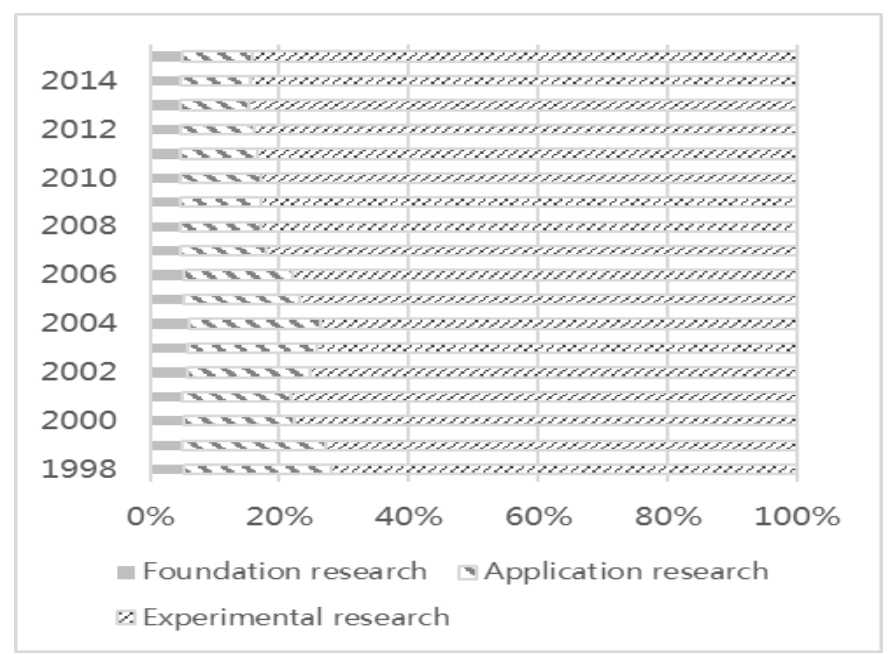

Fig .8 Expenditure ratio of foundation research in 1998-2015 of China

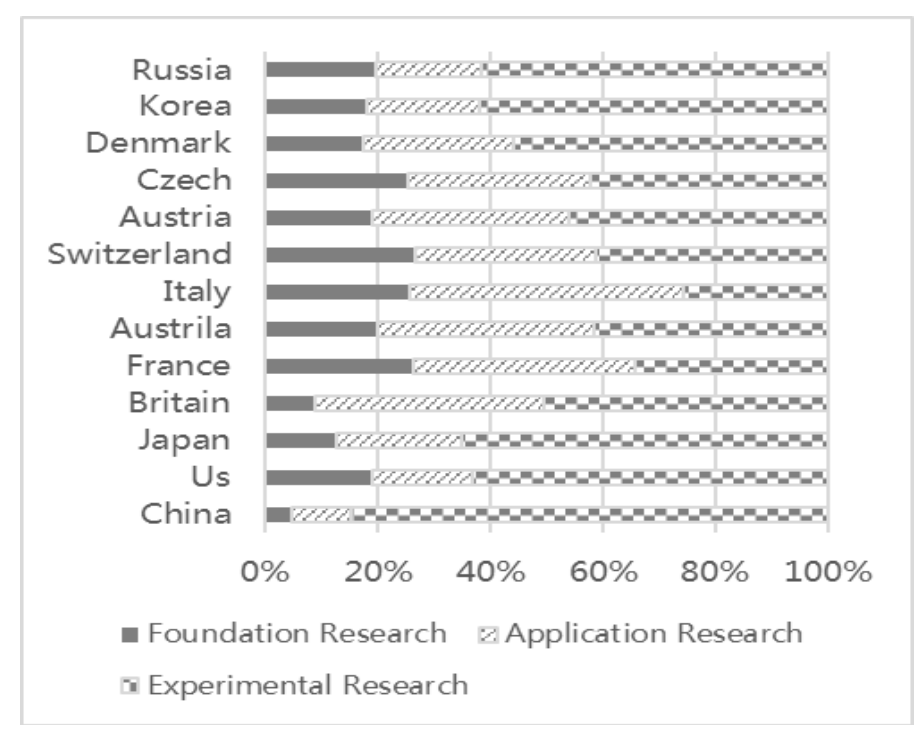

Fig.9 The proportion of foundation research expenditure in the major countries of the world in 2016

The advantage of backwardness theory was first put forward in 1962 by Alexander Gerschenkron, an American economic historian. FDI and technology introduction are the main ways to achieve the advantage of backwardness. There has been a lot of empirical research on the impact of FDI for the TFP, indicating that FDI will bring technology spillover to promote the local total factor productivity. In the aspect of technology introduction, since the entry of the new century, although the expenditure of technology import has remained stable, but considering that the expenditure of scientific research has increased substantially, the R\&D expenditure proportion of technology import has been decreasing year by year, as shown in Figure 10. 


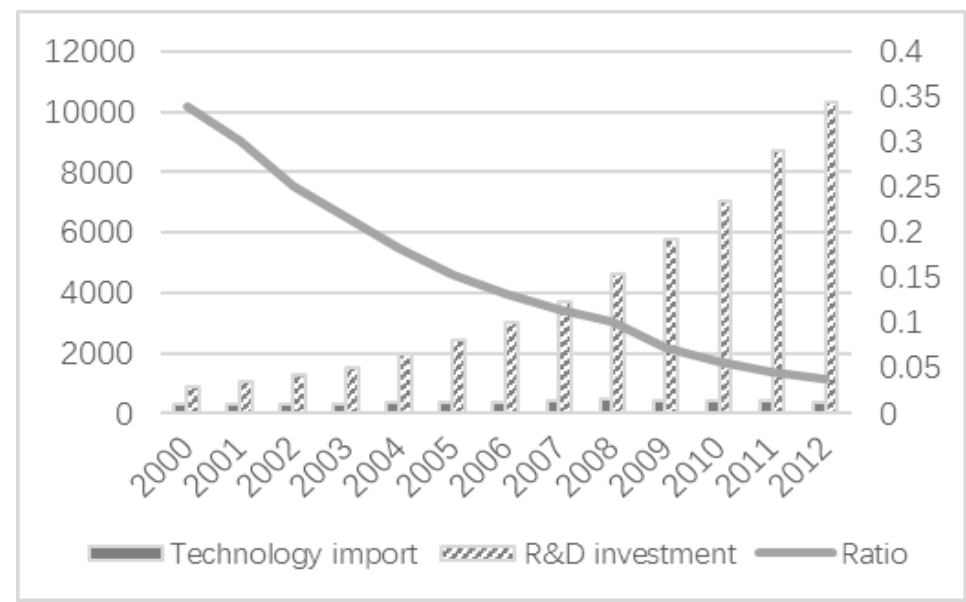

Fig.10 Changes of technology introduction expenditure

Meanwhile, although the contribution rate of TFP to GDP growth is relatively stable, it relies mainly on the improvement of scale efficiency and allocation efficiency. There is a gradually decreases in terms of technological progress, as shown in Figure 11. Comparing the cost ratio of the introduction of technology and the rate of technological progress between 2000-2010, it is found that these statistics were positively correlated and the correlation coefficient was 0.945 , as shown in Figure 12. The above comparison also showed that technological progress in China was also dependent on technology import. The situation of independent technological innovation supporting technological progress has not yet formed. At present, technological innovation reserve is mainly dependent on technology import.

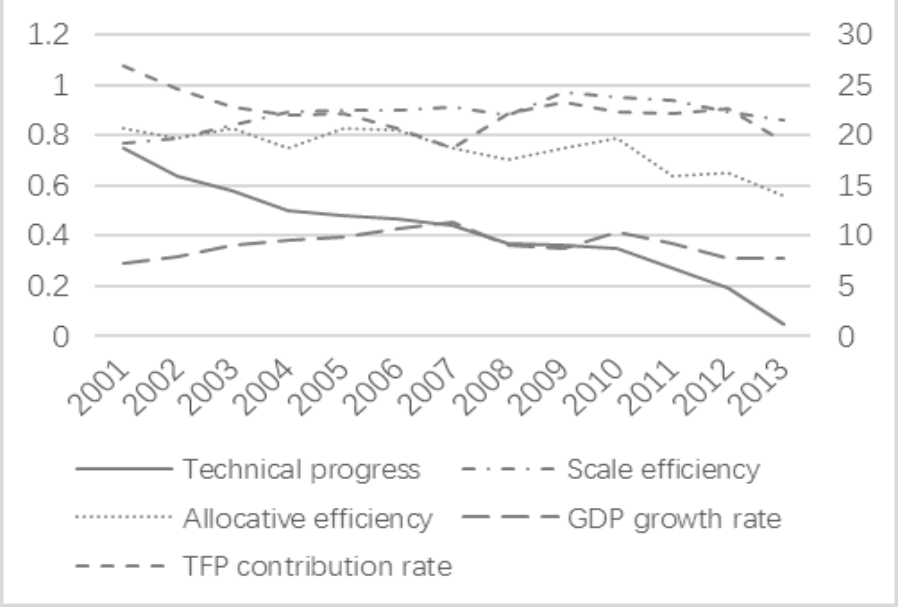

Fig.11 Diagram of total factor productivity decomposition

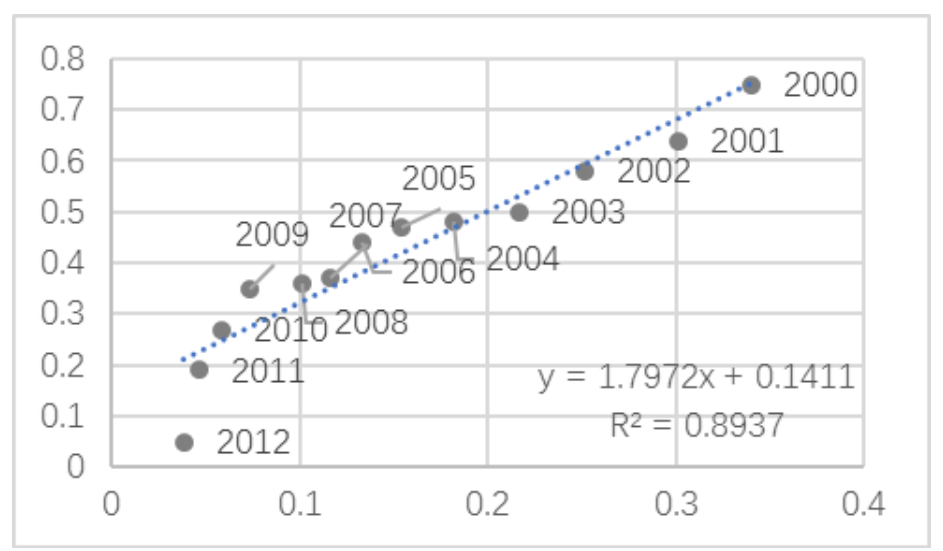

Fig.12 Comparison of technology import ratio and technological progress rate 


\section{Conclusions and Suggestions}

This paper briefly analyzes the current situation of technology innovation in China's manufacturing industry, points out that China is a big country but not a power country in the field of innovation. Based on the comparison of the statistics such as TFP, patents number, financial aggregation level, this paper also demonstrates the relationships between the weak innovation ability and the R\&D expenditure structure, financial support, technological innovation reserves. According to the above analysis conclusion, the following suggestions are put forward for the construction of innovation ability in manufacturing industry.

\section{Continuously Optimize the Technological Innovation Expenditure Structure}

First, continuously increase the investment of technological innovation funds, especially improve the proportion of foundation research investment. Because the foundation research can hardly attract the investment from enterprises and social institutions as it is not aimed at market profit, more state and local governments supporting financial funds are needed. Second, optimize the industrial structure of technological innovation expenditure, and gradually tilt to the field of high value-added and high technology content. Third, adjust the R\&D expenditure enterprise, gradually reduce the expenditure of equipment and other hardware facilities, and turn the enterprise innovation from the experimental type to the research type.

\section{Establish a Perfect Financing System for Technological Innovation}

First, construct the corresponding financial system, financial market and financial system, including the construction of multi-level capital market and equity financing market considering the characteristic and demand of manufacturing industry. Establish and improve the technology financial system and service platform such technology equity, venture capital, enterprise merger and acquisition, etc. Second, study and formulate the fund tilt mechanism, provide financing support for the small and medium-sized innovative enterprises through the government guidance fund, discount subsidy and other ways. Third, aiming at the characteristics of manufacturing industry such as long investment return cycle and high risk, improve the risk compensation and share mechanism, build effective credit structure. Fourth, create a financial environment which is benefit for innovation. Under the premise of clear regulatory requirements, encourage all kinds of financial institutions to introduce supporting products and services, including intellectual property pledge financing, entrepreneurship insurance and so on.

\section{Improve the Results Transfer and Knowledge Spillover Mechanism}

First, strengthen the mechanism system of intellectual property and enterprise secret protection, build institutional protection of scarce resources with enterprise characteristics, and encourage enterprises to carry out technological innovation. Second, promote cluster learning, reduce the silence, specificity and particularity of knowledge, improve the transfer of innovative resources and achievements. Third, create an open talent resources market, smooth the introduction and circulation mechanism of talent. Improve the incentive mechanism of technological innovation, promote the full flow of talents by allowing professors and other researchers to work part-time, and speed up the transformation of research results. Forth, construct the technology trading platform, diversify the transfer of knowledge and knowledge spillover, and improve the effective utilization of innovation.

\section{Reference}

[1] ZHONG Shuhua. Innovative clusters: conception, character and theoretical meaning[J]. Studies in Science of Science,2008,(01):178-184.

[2] Liu Mingkang, Chen yongwei. The situation, problem and strategy of TFP in China[J]. Comparative Studies, 2016,84(3):11-19. 
[3] Ding Yibing, Fu Yingjie, Cao Ye. Financial Constraint, Technological Innovation and Stepping Over the Middle Income Trap-An Industrial Structure Upgrading Perspective[J]. Industrial Economics Research, 2014, (03):101-110.

[4] Liu Yun, An Jing, Chen Wenjun. Management System, Fund Input and Allocation Patterns of U.S. Basic Research and Its Apocalypse to China[J]. China Basic Science,2013,(03):42-52.

[5] Yang Jianbo. Research on R\&D, Innovation and China's TFP[D]. Huazhong University of Science and Technology, 2009.

[6] Christensen JF. Asset profiles for technological innovation[J]. Research Policy. 1995,Volume 24(5): 727-745.

[7] Lawless MJ, Fisher RJ. Sources of durable competitive advantage in new products[J].Journal of Product Innovation Management. 1990, (7):35-43.

[8] Griliches Z. Issues in Assessing the Contributions of Research and Development to Productivity Growth[J]. Bell Journal of Economics. 1979, (10) : 92-116.

[9] Aghion and Howitt. A model of growth through creative destruction[J]. Econometric. 1992,60: 323-351.

[10]Feng Yunting, Chen Changzhi. Spatial structure and spatial correlation analysis of urban TFP [J]. Research on Financial and Economic Issues. 2016,(05):110-115.

[11]Zhao Zongyuan. Research on the impact of financial agglomeration on the growth of TFP in manufacturing industry[D]. Shanghai Normal University, 2016.

[12]Ru Lefeng, Miao Changhong. Research on the Level and Spatial Pattern of Financial Agglomeration on Central Cities in China [J]. ECONOMIC GEOGRAPHY,2014,34(02):58-66. 